\title{
USING WARNING DEVICES TO IMPROVE PRESSURE-RELIEF TRAINING
}

\author{
By J. C. Chawla, M.D., F.R.C.S., B. Andrews, M.Sc., and C. Bar, M.Sc. \\ Rookwood Hospital, Cardiff, Wales
}

\begin{abstract}
A training and monitoring system has been developed to train spinal cord injured patients to relieve pressure intermittently from ischium while sitting in wheelchairs. The system automates the training of wheelchair push-ups based on certain conditioning principles. The system reminds the patient to do a push-up of a specified duration and at specified intervals. The frequency and the duration of the push-ups are monitored providing information about performance of the patients, especially when the alarms to remind the patients are disconnected. A long-term study is in hand to assess the effectiveness of the system.
\end{abstract}

Key words: Pressure relief training; Wheelchair push-ups.

\section{Introduction}

ONE of the aims of management of the spinal cord injured patients is prevention of pressure sores. The development of ischial decubitus ulcers still remains a significant problem in patients who remain seated for long prolonged periods. The intermittent relief of pressure, for the prevention of pressure sores, is a well established clinical fact. The paraplegic patients learn to perform push-ups and the tetraplegics, who cannot do push-ups, relieve pressure by leaning to one side or the other. While in hospital, the patients receive reminders from the staff to perform the pressure relief exercises, but the successful outcome depends upon how well the patient has learned the significance of periodic pressure relief.

Learning refers to a more or less permanent change in behaviour which occurs as a result of practice. It has been shown that learning is incremental and that the response becomes more probable as the trials continue. Furthermore, repetition is necessary for the strengthening of the response (Kimble, I96I). Several devices, based on certain learning principles, have been developed and these aim to train patients to perform periodic relief of presures regularly. Fordyce and Simons (I968) produced a device which offered a choice of I0- or 20-min intervals between push-ups while the duaration of the push-up demanded could be selected as either 5 or Io sec. Feed-back was provided via an audio-tone. If the patient sustained pressure relief for the required period, a push-up was recorded. Patterson and Sradal (1973) produced a similar model which emitted an audio warning when the patient had remained seated continuously for Io min. The device was automatically reset when the seat pressure was removed for $4 \mathrm{sec}$. No monitoring or recording facilities were available with this device. Malament, Michael and Ross (1975) developed a system which delivered a $30-\mathrm{sec}$ audio alarm pulse to the patient upon his failure to push-up during a Io-min period. The alarm could be terminated if the patient performed a push-up but the duration of the push-up needed to be at least $4 \mathrm{sec}$ in order to activate the recording equipment. Each time the alarm sounded the event was recorded. Temes and Harder (1977) developed a device that gave an audio 
warning (i.e. buzzer) if pressure was not relieved for $30 \mathrm{sec}$ in a period of $30 \mathrm{~min}$. Once the buzzer sounded the timer reset automatically for another $30 \mathrm{~min}$ period. The device monitored the number of times the buzzer sounded, the number of push-ups performed regardless of their duration, and the number of times that pressure relief of 30 sec or more occurred.

Black (I978) is developing a system which demands I min of accumulated pressure relief for every $15 \mathrm{~min}$ of continuous sitting. This may be achieved by lifting for short periods of time during a 15-min interval. Feed-back is supplied via a warning light if the accumulated sitting time is less than I min in $15 \mathrm{~min}$ and an audio alarm if the accumulated sitting time is less than I min in $16 \mathrm{~min}$. The device records the number of lifts performed, the total sitting time and the total sitting time in error.

A device for use by patients who cannot perform a push-up but must lean to one side or the other to relieve pressure was proposed by Roemer et al. (1976). This device involved two sequential warnings: the first being a light emitting diode which indicated which side the patient should relieve pressure and secondly an audio alarm which turned on if the patient did not heed the light display. Separate adjustable time periods were available for the pressure relief duration and the interval between pressure relief.

Although these devices have been developed to train the patients, only Malament et al. (1975) has published any details on the clinical evaluation and his study group consisted of five spinal injured patients of which only two completed the programme.

The system employed in this study was developed to automate the training of periodic relief of pressure in the seating position. It is based on the same principles as the other devices reported in the literature. However, some of the other devices have not employed immediate reinforcement, but have incorporated a latent time between response and reinforcement and did not monitor the error rate. In the design of the present system, we considered it important that the training and monitoring of the patients should simultaneously take place. The monitoring facilities were considered essential in order to establish levels of performance as the training progressed.

Although, we have developed systems for training and monitoring paraplegics and tetraplegics, this paper is based on the results obtained from paraplegic patients who can perform push-ups.

\section{The Training and the Monitoring System}

The system consists of a pressure mat (Fig. I) which is placed on the seat of the wheelchair and transfers relief events to a monitor which is designed to fit the wheelchair (Fig. 2), and an alarm system. The alarm system consists of a light source (Fig. I) and an audio tone. The light is situated on the arm of the wheelchair and is visible to the patient. The monitor consists of four counters $\left(\mathrm{C}_{1}, \mathrm{C}_{2}, \mathrm{C}_{3}, \mathrm{C}_{4}\right)$.

The light turns on to warn the patients to relieve pressure if he has remained seated continuously for Io min and stays on until the pressure is relieved. The counter (CI) records the number of times the light comes on.

If the patient ignores this initial warning, the audio alarm sounds for $5 \mathrm{sec}$ after a further $30 \mathrm{sec}$ has elapsed to remind the patient to perform a push-up. This alarm sounds for $5 \mathrm{sec}$ in every $30 \mathrm{sec}$ until pressure relief occurs. Each time the alarm is given, it is recorded and at the end of each session an accumulated 
error count is shown by counter $\mathrm{C}_{2}$. The counter $\mathrm{C}_{3}$ records when the pressure is relieved of the pressure mat. The alarm system is switched off and the Io-min timer resets. If the patient sits down before the full $20 \mathrm{sec}$ is completed, the audio alarm is again sounded. This audio alarm warns the patient that he has not relieved pressure for a sufficiently long enough period of time; the alarm will continue to sound for the remainder of the $20 \mathrm{sec}$ for which he is in error. If he pushed up again the alarm stops. An incremental count is made in counter

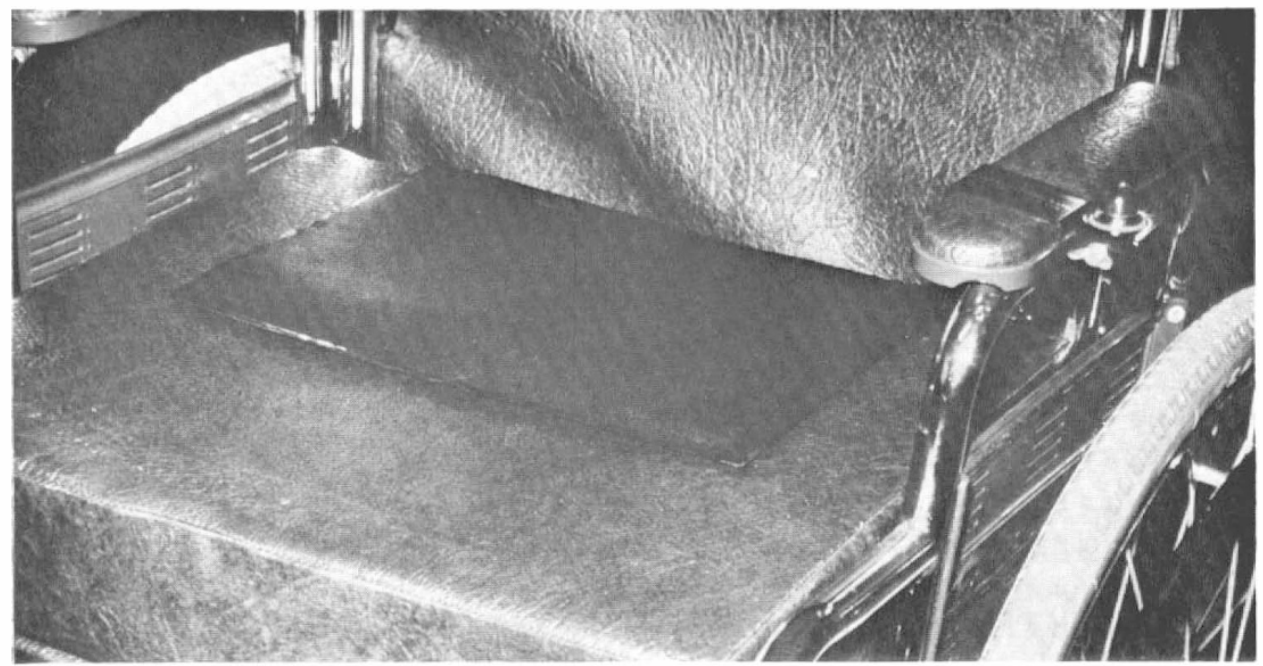

FIG. I

Showing pressure mat on the seat and warning light fixed to the arm of the wheelchair.

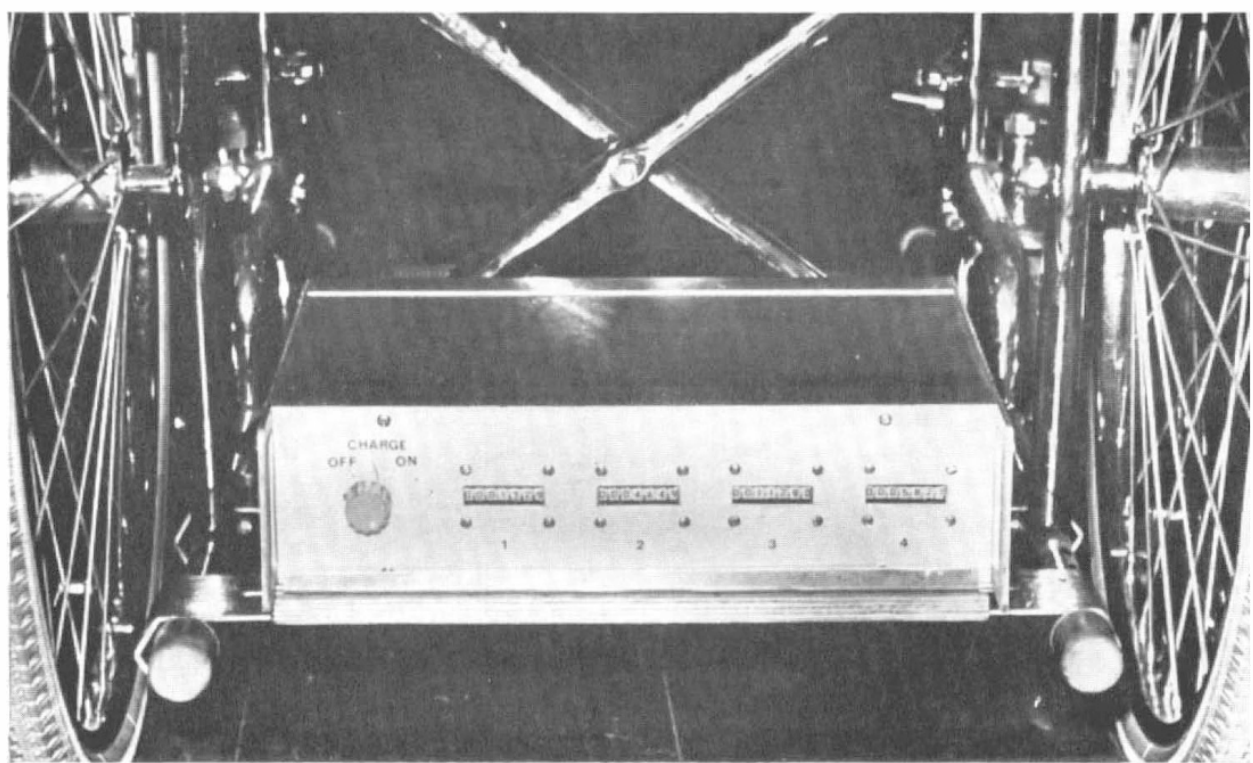

Fig. 2

Showing the monitor incorporating counters I, 2, 3, 4 . 
$\mathrm{C}_{4}$ every $5 \mathrm{sec}$ while the patient is in error (i.e. sitting) of the $20 \mathrm{sec}$. At the end of each session an accumulated sitting error time is thus stored in $\mathrm{C}_{4}$.

Each push-up postpones the onset of an alarm by Io min and initiates the 20-sec push-up timer. It follows that a patient can perform a lift at any time and does not have to wait for an alarm.

A 2-sec delay is incorporated in the circuit such that a push-up is not registered unless pressure is relieved for more than $2 \mathrm{sec}$. This is necessary to give the patient some flexibility of movement so as not to record such activities as washing hair, playing table tennis, picking up an object off the floor.

\section{Materials and Method}

The study group consisted of ten spinal cord injured patients including three with a history of pressure sores (Table I). Selection for the training programme was based on the following criteria: (a) each patient perform a push-up; (b) no sensation was felt around the ischial and sacral areas; and (c) each patient agreed to participate in the programme. Intelligence levels, age and motivation were not considered in the selection of patients.

The programme to evaluate a patient's push-up performance while training him to improve the regularity of these exercises involved three phases:

Phase I: During this phase, no feedback is given and the patient's existing push-up performance is monitored so that comparisons of performance can be made throughout subsequent phases of treatment.

Phase 2: The alarms are activated and the patient is instructed to try and prevent the alarms from going off. The patient's movements are monitored throughout this phase so that the effect of feedback on the exercise performance can be observed.

Phase 3: The alarms are de-activated without the patient's knowledge but monitoring is continued to allow the patient's performance to be assessed.

TABLE I

The study group

\begin{tabular}{|c|c|c|c|c|c|}
\hline No. & Age & Sex & Date of injury & Level of injury & $\begin{array}{l}\text { Previous history } \\
\text { of sores }\end{array}$ \\
\hline I & I 8 & Male & I. 4.77 & $\mathrm{~T} 8 / \mathrm{To}$ & None \\
\hline 2 & I9 & Male & 19.7 .76 & $\mathrm{LI}$ & Ischial \\
\hline 3 & 28 & Male & 21.6.77 & $\mathrm{C} 8$ & None \\
\hline 4 & 54 & Male & 22.7 .77 & $\mathrm{LI} / \mathrm{L}_{4}$ & None \\
\hline 5 & 20 & Male & 9.8 .77 & TI2/LI & None \\
\hline 6 & 25 & Male & $7 \cdot 4 \cdot 77$ & TI2/LI & None \\
\hline 7 & 16 & Male & 1966 & T9 & $\begin{array}{l}\text { Recurring ischial } \\
\text { sores from I97I on }\end{array}$ \\
\hline 8 & $2 I$ & Male & I I.9.77 & $\mathrm{T} 6 / \mathrm{T}_{7}$ & None \\
\hline 9 & I9 & Male & & $\begin{array}{l}\text { Cervical cord } \\
\text { tumour }\end{array}$ & Sacral \\
\hline IO & I6 & Male & 5.1 .78 & $\mathrm{~T}_{3} / \mathrm{T}_{4}$ & None \\
\hline
\end{tabular}




\section{Results}

The results obtained from the three phases of the training programme, and those obtained from the five patients on follow-up are summarised in Tables II and III. The statistical analysis of the results suggests that:

(a) There was a significant increase $(t=2 \cdot 23)$ in the number of ro-min alarms received in Phase 3 compared to Phase I. The number of Io-min alarms decreased in the follow-up phase compared to Phase 3 which may be significant $(t=\mathrm{I} \cdot 8)$.

\section{TABLE II}

No. Mean no. of Io-min alarms/hr. Mean no. of cumulative IO-min errors

Follow-up
phase Ph. I Ph. 2 Ph. 3 pollow-up

Ph. I Ph. 2 Ph. 3 phase Ph. I Ph. 2 Ph. 3 phase

\begin{tabular}{|c|c|c|c|c|c|c|c|c|}
\hline I & $0 \cdot 7$ & $2 \cdot 8$ & $\mathrm{I} \cdot 8$ & $I \cdot O$ & $5 \cdot I$ & $\mathrm{I} \cdot 7$ & $2 \cdot 8$ & 0.0 \\
\hline 2 & $2 \cdot I$ & $4 \cdot 5$ & $3 \cdot 3$ & $3 \cdot 0$ & $4 \mathrm{I} \cdot 2$ & $3 \cdot 0$ & $33 \cdot 0$ & II $\cdot O$ \\
\hline 3 & $2 \cdot I$ & $4 \cdot 4$ & $3 \cdot 7$ & & $59 \cdot 4$ & $2 \cdot 6$ & $33 \cdot 3$ & \\
\hline 4 & I. 4 & $4 \cdot 6$ & $3 \cdot 3$ & $I \cdot O$ & 14.7 & $2 \cdot 0$ & $23 \cdot 8$ & $4 \cdot 0$ \\
\hline 5 & $2 \cdot I$ & $5 \cdot I$ & $3 \cdot 7$ & $3 \cdot 5$ & $38 \cdot 0$ & $2 \cdot 9$ & 10.5 & $5 \cdot 0$ \\
\hline 6 & $I \cdot 3$ & $5 \cdot 0$ & 3.8 & & $19 \cdot 2$ & 0.5 & 0.5 & \\
\hline 7 & 0.6 & $I \cdot O$ & $I \cdot 6$ & & $I \cdot 2$ & 0.5 & $2 \cdot 7$ & \\
\hline 8 & $3 \cdot 7$ & $3 \cdot 2$ & $3 \cdot 2$ & $I \cdot 3$ & 14.3 & 0.5 & $2 \cdot 0$ & $7 \cdot 0$ \\
\hline 9 & $\mathrm{I} \cdot 5$ & $2 \cdot I$ & $3 \cdot I$ & & $2 \cdot 5$ & 0.37 & $4 \cdot 3$ & \\
\hline IO & $2 \cdot 4$ & $2 \cdot I$ & $2 \cdot 6$ & & I $7 \cdot 4$ & 0.2 & 0.3 & \\
\hline Mean & $2 \pm$ & & $3 \pm I$ & $2 \pm I$ & $2 \mathrm{I} \pm \mathrm{I} 8$ & & $I I \pm I 3$ & $5 \pm$ \\
\hline
\end{tabular}

TABLE III

\begin{tabular}{|c|c|c|c|c|c|c|c|c|}
\hline \multirow[t]{2}{*}{ No. } & \multicolumn{4}{|c|}{ Mean no. of push-ups $/ \mathrm{hr}$. } & \multicolumn{4}{|c|}{$\begin{array}{l}\text { Mean no. of cumulative } \\
\text { push-up errors }\end{array}$} \\
\hline & Ph. I & Ph. 2 & Ph. 3 & $\begin{array}{l}\text { Follow-up } \\
\text { phase }\end{array}$ & Ph. I & Ph. 2 & Ph. 3 & $\begin{array}{l}\text { Follow-up } \\
\text { phase }\end{array}$ \\
\hline & $-\cdots$ & . & $\ldots$ & 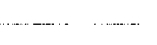 & & $\cdots$ & & $-\cdots$ \\
\hline I & $17 \cdot 3$ & $\mathrm{I} 2 \cdot 2$ & IO 4 & $10 \cdot 0$ & $35 \cdot 9$ & $4 \cdot 0$ & $3 \cdot 0$ & $6 \cdot 0$ \\
\hline 2 & $7 \cdot 7$ & $9 \cdot 6$ & $5 \cdot 0$ & 8.0 & $22 \cdot 0$ & $3 \cdot I$ & 3.5 & $25 \cdot 0$ \\
\hline 3 & 3.0 & $6 \cdot 0$ & $5 \cdot 5$ & & $9 \cdot 4$ & $2 \cdot 0$ & 4.5 & \\
\hline 4 & $17 \cdot 8$ & $9 \cdot 5$ & 13.8 & $18 \cdot 0$ & $46 \cdot 2$ & $I \cdot 9$ & $3 \cdot 8$ & II $\cdot 5$ \\
\hline 5 & $6 \cdot 7$ & $7 \cdot 9$ & $6 \cdot 0$ & $6 \cdot 5$ & 10.6 & $2 \cdot 5$ & $2 \cdot 0$ & $2 \cdot 0$ \\
\hline 6 & 9.6 & $9 \cdot 6$ & $\mathrm{I} 4.6$ & & 15.3 & $2 \cdot 3$ & $2 \cdot 0$ & \\
\hline 7 & $\mathrm{I} 4 \cdot 8$ & 13.3 & 10.9 & & 13.0 & $2 \cdot I$ & $6 \cdot 7$ & \\
\hline 8 & $5 \cdot 8$ & $9 \cdot 0$ & I3.I & $8 \cdot 2$ & $2 \cdot 8$ & $I \cdot O$ & 0.5 & 0.0 \\
\hline 9 & 13.9 & 13.0 & 13.0 & & $9 \cdot 8$ & $\mathrm{I} \cdot 8$ & 8.9 & \\
\hline IO & $12 \cdot 5$ & II $\cdot 0$ & $16 \cdot 2$ & & $4 \cdot 0$ & $0 \cdot 7$ & $2 \cdot 7$ & \\
\hline Mean & II \pm 5 & $10 \pm 3$ & 3 II \pm 4 & $10 \pm 4$ & $\mathbf{I} 7 \pm$ & & $4 \pm 2$ & $9 \pm 9$ \\
\hline
\end{tabular}


(b) No significant difference is observed between the mean number of 10-min errors for either Phase I and Phase 3 or Phase 3 and the follow-up phase.

(c) No significant differences is apparent for the mean number of push-ups between all phases of the trial.

(d) The mean number of cumulative push-up errors significantly decreased in Phase 3 as compared to Phase $\mathbf{I}(t=2 \cdot 5)$. At 3 -month follow-up, there is a small increase in the number of cumulative push-up errors and this may be of some significance $(t=\mathrm{I} \cdot 5)$.

\section{Discussion}

The results obtained so far indicate that although patients performed push-ups to relieve pressure, these tended to be at irregular intervals and of short durations. This was evident during the initial phase and to some extent in the Phase 3. This same fact has been observed by Malament et al. (1975) indicating that the patients have tendency not to relieve pressure regularly in spite of repeated verbal instructions. On introduction of alarms, the push-ups became regular at the specified intervals and the patient's response was immediate. However, Malament et al. (1975) reported that when the alarms were first connected there was a gradual increase in the rate of push-ups. We suggest that this may bedue to the age difference of the study groups. The patients who participated in this study were under the age of 25 except two, aged 28 and 54. The average age of Malament's study group was 42 years. Younger people usually find it easier to either learn or relearn a habit. Wooldrige et al. (1976) have reported that an individual's performance in a learning system increases rapidly with decreasing age. This may be a relevant point for these results where a learning situation is involved.

All the patients, except no. 8, showed a definite tendency to become increasingly dependent on the IO-min alarm as the Phase 2 progresses. It appears that the patients were able to train themselves so that they sustained pressure relief for $20 \mathrm{sec}$ but found it harder to ensure a push-up was performed every ro min. Thus, the IO-min alarm was a useful reminder. The results for Phase 3 support this because the number and the duration of push-ups remained steady but the period of time between push-ups became irregular. Similar observations were made on follow-up assessments of five patients. It showed that the number of IO-min alarms that would have been received did not significantly change and the Io-min errors decreased except for patient no. 8. There was no significant change in the number of push-ups but there appears to be an increase in the number of push-up errors for patients no. I, 2 and 4.

Patients nos. 5 and 8 showed consistent performances throughout the training programme. This may have been due to the fact that these patients entered the programme as soon as they were allowed out of bed. We feel that such a system would enable the patient to develop habit of relieving pressure regularly.

The patients who had irregular patterns of pressure relief in Phase I showed a tendency to resort back to them in Phase 3 (Patients 2 and 3). One of them (2) has developed a sore 6 months after discharge from hospital. Patient no. 7 entered this programme after spending a period in bed because of an ischial sore. His performance was very good (except for the push-up errors which were high). This was probably due to the constant reminders he received from the staff and having just recovered from a sore, he might have been particularly conscious of the consequences of not relieving pressure regularly. However, during Phase 3 the errors increased more than in either of the other two phases. He has also developed a pressure sore recently. The monitoring of patients nos. 2 and 7 
would suggest that a group of patients require constant reminders to relieve pressures even after they have been discharged from hospital. We are in the process of developing a device which would remind the patients to relieve pressure and could be given to them when discharged from hospital.

The incidence of intermittent relief of pressure by the seated patients appears to depend upon the frequency of reminders he receives and his response. Since this is a habit that has to be learned, because it is not one that occurs before injury, the environment in which the patient underwent his initial training will be partly represented in the results for Phase I. We feel that patients have a tendency not to relieve pressure at regular intervals in spite of verbal instructions and that visual audio reminders may help to improve the pressure awareness of the patients.

\section{RÉSUMÉ}

On a développé un systéme d'éducation et de surveillance, qui apprend aux patients blessés au cordon medullaire, à soulager par intervalles, la pression sur les fesses, pendant qu'ils sont assis dans un fauteuil roulant. Lesystéme, fondé sur des principes de conditionnement, rend automatique l'éducation du soulagement de la pression dans un fauteuil roulant. Le systéme rappéle au patient de se soulever pour une durée fixe at aux intervalles prescrites. On surveille la fréquence et la durée des soulevements pour se renseigner sur la performance des patients, particuliérement quand on arrête les signaux qui les avertissent. On est en train de faire une étude d'ensemble pour évaluer le systéme.

\section{ZUSAMMENFASSUNG}

Ein Training-und Warnungsystem ist beschrieben, um Ischiumruck bei Patienten mit Rückenmarksschädigungen zn erleichtern. Das System automatisiert das Hochdrücken des Patienten im Rollstuhl auf Grund bestimmter Principien. Es erinnert den Patienten, sich in Intervallen für gewisse Dauer hoch zu drücken. Häufigkeit und Dauer des Euporhebens werden überwacht, um Information über die Leistung des Patienten zu geben, besonders durch Abstellen des Warnungsalarm. Eine langfristige Untersuchung ist im Gange, um die Brauchbarkeit der Systems zu bewerten.

\section{REFERENCES}

BLACK, R. (1978). Rehabilitation Engineering Department, Ontario Crippled Children's Centre, Toronto. Personal communication.

Fordyce, W. E. \& Simons, B. C. (I968). U.S. Public Health Rep., 83, 527-528.

Kimble, G. A. (196I). Hilgard and Marquiss Conditioning and Learning. AppletonCentury-Crofts, New York.

Malament, I. B., Michael, E. D. \& Ross, D. (1975). Arch. Phys. Med. Rehab., 56, I6I-I65.

Patterson, R. P. \& Stradal, L. C. (I973). Med. Biol. Eng., II, 504-505.

Roemer, R., Lee, H. \& Meisel, H. (I976). Med. Biol. Eng., 8, 580-581.

Temes, W. C. \& Harder, P. (I977). Phys. Ther., 57, I I 52-I I 53.

Wooldridge, C. P. \& Mclaurin, C. A. (1976). Bull. Pros. Res., Spring issue, 25-37. 